\title{
El Ministerio Público y la experiencia peruana en la investigación de delitos de Lesa Humanidad \\ Victor Cubas Villanueva* http://dx.doi.org/10.21503/lex.v9i8.407
}

* Fiscal Superior Penal, coordinador de la Fiscalía Penal Nacional.

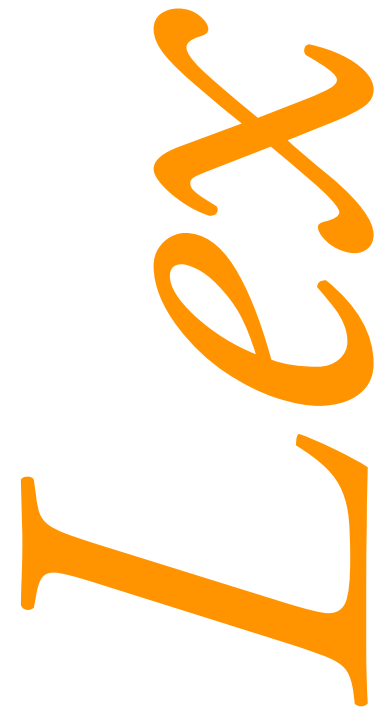



n nuestro país, los tipos penales relacionados a delitos contra la humanidad fueron incorporados aisladamente en el Código Penal de 1991. Así, el delito de Desaparición Forzada lo encontramos en el capítulo correspondiente a delitos de terrorismo; mientras que el Genocidio, en el capítulo correspondiente a delitos contra la vida, el cuerpo y la salud. Hasta entonces, no estuvo previsto el delito de Tortura. Recién, el 21 de febrero de 1998, la Ley No 26926 en su Artículo $1^{\circ}$ incorporó en el Código Penal el Título XIV-A que contiene los Delitos contra la Humanidad, contemplando inicialmente los siguientes:

- Genocidio

- Desaparición Forzada

- Tortura

Los delitos de lesa humanidad están previstos en el artículo $7^{\circ}$ del Estatuto de Roma, ratificado por el Estado peruano el 10 de noviembre del 2001 entrando en vigor el 1 de julio de 2002. Entre ellos se encuentran:

- Asesinato

- Deportación o traslado forzoso de población

- Encarcelación u otra privación grave de la libertad física en violación de normas fundamentales de derecho internacional

- Tortura

- Violación Sexual

- Esclavitud Sexual

- Prostitución forzada

- Embarazo forzado

- Esterilización forzada u otros abusos sexuales de gravedad comparable

- Desaparición forzada de personas

- Crimen de Apartheid 
- Otros actos inhumanos de carácter similar que causen intencionalmente grandes sufrimientos o atenten gravemente contra la integridad física o la salud mental o física.

Para que cualquiera de los hechos antes mencionados se considere como delito de lesa humanidad debe ser a) consecuencia de un ataque generalizado o sistemático cometido en agravio de la población civil y b) el autor debe ser miembro de un órgano de poder estatal o de una organización delictiva que asume el control de facto de un territorio. Por otro lado, debe tenerse en cuenta que estos delitos son imprescriptibles, están sometidos a la Jurisdicción Universal y no pueden ser materia de amnistía ni de indulto.

Precisamente, sobre el último aspecto la Corte Interamericana de Derechos Humanos ha establecido en el Caso Barrios Altos vs. Perú, Sentencia del 14/03/01, Serie C, $n^{\circ} 75$ que:

...son inadmisibles las disposiciones de amnistía, las disposiciones de prescripción y el establecimiento de excluyentes de responsabilidad que pretendan impedir la investigación y sanción de los responsables de las violaciones graves de los derechos humanos tales como la tortura, las ejecuciones sumarias, extralegales o arbitrarias y las desapariciones forzadas, todas ellas prohibidas por contravenir derechos inderogables reconocidos por el derecho internacional de los Derechos Humanos.

En el Caso La Cantuta vs. Perú, Sentencia sobre fondo, reparaciones y costas del 29 de noviembre de 2006, Párrafos 225 y 226, sostiene:

los hechos de la Cantuta, cometidos contra las víctimas ejecutadas extrajudicialmente o desaparecidas forzadamente, constituyen crímenes contra la humanidad que no pueden quedar impunes, son imprescriptibles y no pueden ser comprendidos dentro de una amnistía.

Además agrega que:

en cumplimiento de su obligación de investigar y en su caso sancionar a los responsables de los hechos, el Estado debe remover todos los obstáculos, de facto y de jure, que mantengan la impunidad, y utilizar todos los medios disponibles para hacer expedita la investigación y los procedimientos respectivos y así evitar la repetición de hechos tan graves como los presentes. El Estado no podrá argüir ninguna ley o disposición de Derecho interno para eximirse de la orden de la Corte de investigar y, en su caso, sancionar penalmente a los responsables de la Cantuta. 
El Perú se adhirió a la Convención sobre la Imprescriptibilidad de los Crímenes de Guerra y de los Crímenes de Lesa Humanidad el 11 de agosto de 2003 mediante Resolución Legislativa $N^{\circ} 27998$ con rango de ley. Según lo dispuesto esta norma entraría en vigor el 11 de noviembre de 2003. De acuerdo con la Convención, son imprescriptibles cualquiera que sea la fecha en que se hayan cometido los crímenes de guerra y los crímenes de lesa humanidad cometidos en tiempo de guerra y de paz.

Precisamente en el Preámbulo de dicho instrumento internacional se establece que "los crímenes de lesa humanidad figuran entre los delitos de derecho internacional más graves."

La represión efectiva es un elemento importante para prevenir esos crímenes y proteger los derechos humanos (...) las normas de derecho interno relativas a la prescripción de los delitos ordinarios suscita grave preocupación en la opinión pública mundial, pues impide el enjuiciamiento y castigo de las personas responsables de esos crímenes (...) es necesario y oportuno afirmar en derecho internacional, por medio de la presente Convención, el principio de la imprescriptibilidad de (...) los crímenes de lesa humanidad y asegurar su aplicación universal.

En concordancia con ello, el Estatuto de Roma en su artículo $29^{\circ}$ dispuso que los crímenes de la competencia de la Corte no prescriben.

Por su parte la Corte Interamericana de Derechos Humanos (CIDH), en el Caso Velásquez Rodríguez, ha establecido que

El Estado está en el deber jurídico de prevenir, razonablemente, las violaciones de los derechos humanos, de investigar seriamente con los medios a su alcance las violaciones que se hayan cometido en el ámbito de su jurisdicción a fin de identificar a los responsables, de imponerles las sanciones pertinentes y de asegurar a la victima una adecuada reparación.

Igualmente agrega que:

El Estado está, por otra parte, obligado a investigar toda situación en la que se hayan violado los derechos humanos protegidos por la Convención. Si el aparato del Estado actúa de modo que tal violación quede impune y no se restablezca, en cuanto sea posible, a la víctima en la plenitud de sus derechos, puede afirmarse que ha incumplido el deber de garantizar su libre y pleno ejercicio a las personas sujetas a su jurisdicción. Lo mismo es válido cuando se tolere que los particulares o grupos de ellos actúen libre o impunemente en menoscabo de los derechos humanos reconocidos en la Convención. 
Por su parte nuestro Tribunal Constitucional, en reiterada jurisprudencia, establece que:

La Nación tiene el derecho de conocer la verdad sobre los hechos o acontecimientos injustos y dolorosos provocados por las múltiples formas de violencia estatal y no estatal. Tal derecho se traduce en la posibilidad de conocer las circunstancias de tiempo, modo y lugar en las cuales ellos ocurrieron, así como los motivos que impulsaron a sus autores. El derecho a la verdad es, en ese sentido, un bien jurídico colectivo inalienable.

En los fundamentos de la sentencia emitida al resolver la demanda de inconstitucionalidad del Decreto Legislativo 1057, se sostiene que si el Estado democrático y social de derecho se caracteriza por la defensa de la persona humana y el respeto de su dignidad, es claro que la violación del derecho a la verdad no sólo es cuestión que afecta a las víctimas y a sus familiares, sino a todo el pueblo peruano; de ahí que sea parte del contenido constitucionalmente protegido del derecho fundamental a la verdad, el que los crímenes de lesa humanidad resulten imprescriptibles. Y agrega que:

sobre la base de lo expuesto, debe quedar claro que la regla de imprescriptibilidad de los delitos de lesa humanidad, y consecuentemente, el mandato de su persecución, con prescindencia de la fecha en que aquellos se hayan cometido, no tiene vigencia en el ordenamiento jurídico peruano como consecuencia de la entrada en vigor de la Convención sobre la Imprescriptibilidad de los Crímenes de Guerra y de los Crímenes de Lesa Humanidad (9 de noviembre de 2003), sino que surge en virtud de una norma imperativa de derecho internacional general que, como ha sostenido la Corte Interamericana, no nace de la referida Convención, sino que está reconocida en ella (Cfr. Caso La Cantuta vs. Perú, Sentencia del 29 de noviembre de 2006, párrafo 225).

El Tribunal Constitucional agrega que la declaración contenida en el punto 1.1 del Artículo Único de la Resolución Legislativa № 27998, que aprobó la Convención sobre la Imprescriptibilidad de los Crímenes de Guerra y de los Crímenes de Lesa Humanidad que expresa:

De conformidad con el Artículo 103 de su Constitución Política, el Estado Peruano se adhiere a la Convención sobre la Imprescriptibilidad de los Crímenes de Guerra y de los Crímenes de Lesa Humanidad, adoptada por la Asamblea General de las Naciones Unidas, el 26 de noviembre de 1968, para los crímenes que consagra la convención, cometidos con posterioridad a su entrada en vigor para el Perú", resulta inconstitucional y "habiéndose 
advertido su inconstitucionalidad, y siendo este Colegiado el supremo intérprete de la Constitución, en virtud de los artículos VI del Título Preliminar y $82^{\circ}$ del CPCo., a partir del día siguiente de la publicación de esta sentencia, todo poder público se encuentra impedido de aplicar el referido precepto jurídico". Concluyendo que las leyes inconstitucionales que conceden algún beneficio (...) no podrán desplegar tales efectos porque, siendo el control difuso un poderdeber de toda la judicatura (artículo $138^{\circ}$ de la Constitución), el juez a quien se solicite su aplicación retroactiva deberá inaplicarla por resultar incompatible con la Constitución. La retroactividad benigna sustentada en una ley inconstitucional carece de efectos jurídicos (Cfr. STC 0019-2005-PI, F. J. 52).

La Comisión de la Verdad y Reconciliación recibió el encargo del gobierno de investigar los crímenes y violaciones contra los Derechos Humanos perpetrados desde 1980 hasta el año 2000 como consecuencia del conflicto armado interno que durante esos años sufrió nuestro país. A finales de agosto de 2003, la CVR presentó al país su Informe Final y, de igual manera, presentó ante el Ministerio Público, 47 casos de graves violaciones a los Derechos Humanos para que fueran investigados y denunciados ante el Poder Judicial.

Los casos presentados comprenden los crímenes más graves contra los Derechos Humanos tales como:

- Ejecuciones Arbitrarias y Asesinatos. (Ej. Las ejecuciones de Parco y Pomatambo, la matanza de Pucará, los sucesos de los penales, etc.)

- Desaparición Forzada de Personas y Secuestro, es decir, haber practicado detenciones legales o ilegales y luego haber desaparecido a las personas $(\mathrm{Ej}$. La desaparición de los estudiantes de la Universidad del Centro, de las autoridades de Chuschi, del periodista Jaime Ayala Sulca, etc.).

- Tortura, es decir, infligir a otro dolores o sufrimientos graves físicos o mentales con el fin de obtener de la víctima o de un tercero una confesión o información (Ej. Caso Indalecio Pomatanta, caso Hugo Bustios, caso Cuartel Los Cabitos, etc.)

- Violación Sexual de Mujeres (Ej. el caso de María Magdalena Monteza y las mujeres de Manta y Vilca en Huancavelica).

Los casos presentados, en principio, no fueron investigados oportunamente durante el período comprendido entre los años 1980-2000, pues el sistema judicial fue ineficiente debido básicamente a la existencia de problemas congénitos como, por ejemplo, falta de independencia en la designación de sus funcionarios, deficiente asignación de recursos económicos, morosidad en el trámite de los procesos, excesiva carga procesal, etc. 
Sin embargo, luego de la caída del régimen autoritario, el Ministerio Público, en cumplimiento de su función constitucional, empezó la tarea de investigación de los múltiples casos de violación de los Derechos Humanos. Para el efecto, emitió la Directiva Interna $\mathrm{N}^{\circ}$ 011-MP-FN que regula la Investigación Fiscal frente al hallazgo de fosas que guardaban relación con graves violaciones a los Derechos Humanos.

Asimismo, por Resoluciones de Fiscalía de la Nación Nos. 1645-2004-MP-FN y 1602-2005-MP-FN en el año 2004 se crearon las fiscalías especializadas para la investigación de graves casos de violaciones a los Derechos Humanos y, a la fecha, existe el Subsistema Especializado integrado por tres Fiscalías Superiores con competencia nacional y nueve Fiscalías Penales Supraprovinciales en los departamentos de Lima, Ayacucho, Huancavelica, Junín y Huánuco.

Una decisión fundamental ha sido la creación por Resolución de la Fiscalía de la Nación $\mathrm{N}^{\circ}$ 1262-2003-MP-FN el 13 de agosto del 2003 del Equipo Forense Especializado que, en la actualidad, está integrado por 49 profesionales. Este equipo constituye un conjunto multidisciplinario de profesionales de las siguientes aéreas: Medicina Legal, Odontología Forense, Antropología Social, Antropología Forense, Arqueología Forense, Fotografía Forense y Psicología. Todos los profesionales que integran este equipo cuentan con amplia experiencia en sus respectivos campos y han sido entrenados y capacitados complementariamente en el campo de investigaciones de graves violaciones a los Derechos Humanos.

Las funciones del Equipo Forense Especializado son la búsqueda, recuperación, identificación de restos humanos de personas desaparecidas. Para este fin, ha elaborado estrategias de intervención forense a gran escala tomando como referencia las áreas geográficas donde se encuentran los casos que incluyen:

a. La ubicación de las fosas que contienen restos de las personas desaparecidas.

b. La elaboración de fichas antemortem de las personas desaparecidas.

c. Demás especificaciones de la investigación forense que llevan al éxito de la exhumación y posterior identificación de los desaparecidos.

Los procedimientos han facilitado la investigación médico legal y, por ende, la investigación fiscal, haciendo posible el trabajo en varios casos al mismo tiempo y, hasta la fecha, se han recuperado los cuerpos de aproximadamente 1,800 personas, de las cuales más del $50 \%$ ha sido plenamente identificadas. Esto ha permitido la entrega de los restos a sus familiares, para que les den sepultura conforme a sus costumbres y creencias y humanamente cierren así su círculo de luto. En nuestro país, el número de personas desaparecidas durante las dos 
décadas de conflicto armado, según estimaciones de la Comisión de la Verdad y Reconciliación y otros organismos de defensa de los Derechos Humanos, es de aproximadamente 15,000.

El Equipo Forense Especializado cuenta con una base de datos que utiliza el software AM/ PM (antemortem/postmortem) donado por el Comité Internacional de la Cruz Roja (CICR). Este software, entre sus muchas funciones, permite el ingreso de nuevos casos de personas desaparecidas y evita que una misma persona desaparecida ingrese dos veces como caso nuevo.

En la ciudad de Huamanga, en el departamento de Ayacucho, el Ministerio Público tiene un moderno Laboratorio de Investigaciones Forenses cuya infraestructura cuenta con cuatro pisos implementados y equipados adecuadamente. Actualmente, cuenta con tecnología para realizar análisis de $\mathrm{ADN}$.

Las muestras de $\mathrm{ADN}$ que se han venido recolectando a lo largo de todos estos años se encuentran debidamente ordenadas y clasificadas por el Laboratorio de Biología Molecular y ADN del Instituto de Medicina Legal. Sin embargo, parte de los restos óseos encontrados y exhumados han sido sometidos a análisis de ADN en laboratorios de los Estados Unidos de Norte América.

En los procesos de investigación llevados a cabo por el Ministerio Publico, los familiares de las víctimas han contado con acompañamiento psicológico y social. Además los restos humanos identificados han sido entregados a sus familiares conjuntamente con los documentos oficiales como el protocolo de necropsia y la partida de defunción, los que les sirve para realizar las gestiones ante la Comisión Nacional de Reparaciones creada por Ley $\mathrm{N}^{\circ} 28592$ del 29 de julio del 2005.

En todo el proceso de investigación de violaciones de Derechos Humanos, el Ministerio Público viene contando con la estrecha colaboración de instituciones como el Comité Internacional de la Cruz Roja, el Equipo Peruano de Antología Forense y CENIA, que colaboran en tareas de investigación antropológico forense, es decir, la recuperación de restos humanos, el proceso de identificación y la entrega a sus familiares.

En conclusión, el Ministerio Público viene llevando a cabo el proceso de investigación en los diferentes casos de violación a los DD.HH. a nivel nacional y, en los casos de Desaparición Forzada, cuenta con un plan de intervención antropológico forense ejecutado por profesionales del EFE que vienen trabajando bajo la dirección de los Fiscales que conforman el Subsistema Especializado. 


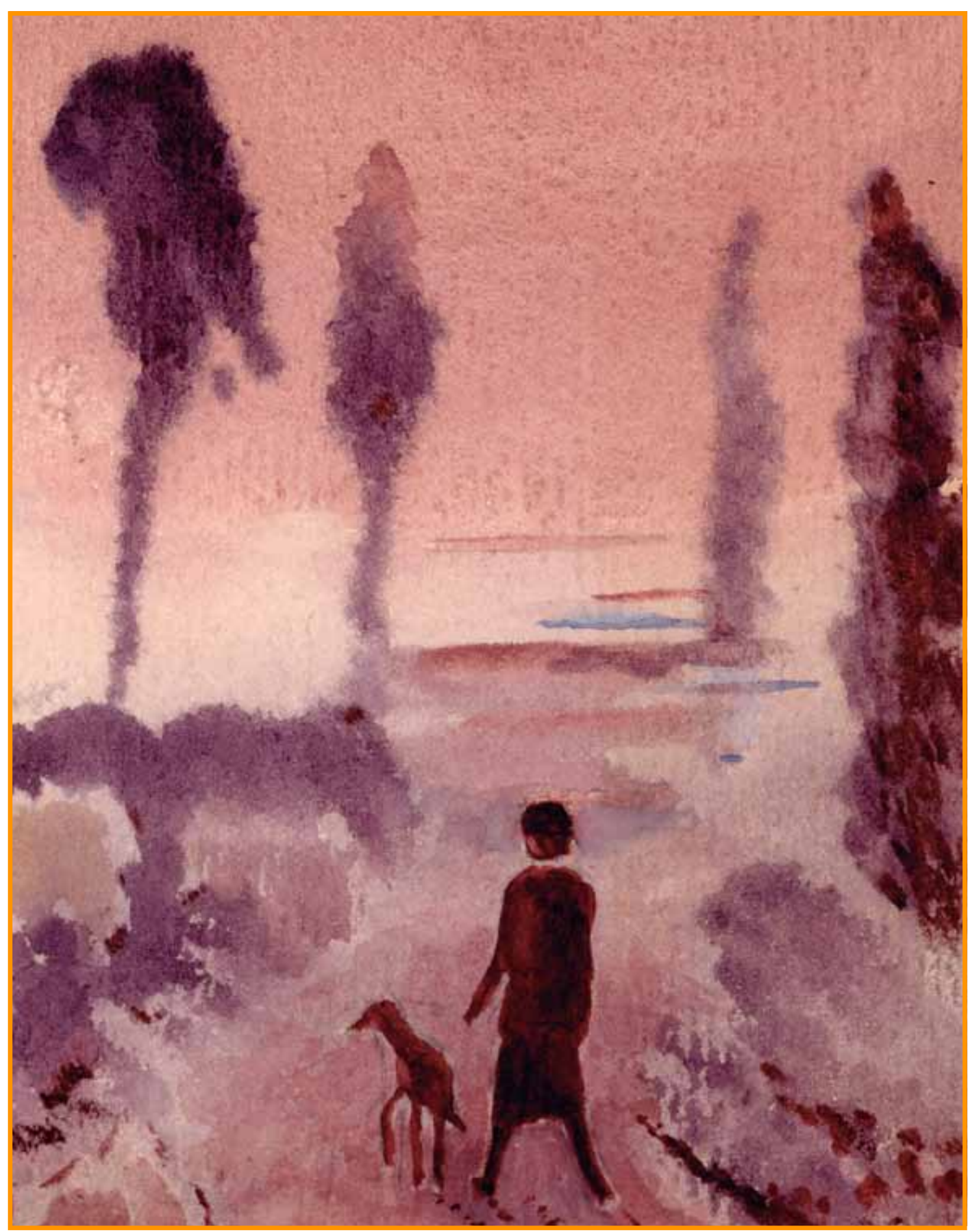

Con su fiel perro 